\title{
Esto le puede servir a alguien. Demandas de derechos en el espectáculo televisivo contemporáneo en Argentina
}

\author{
Carolina Justo von Lurzer \\ CONICET - UBA, Argentina \\ E-mail: justocarolina@gmail.com
}

\begin{abstract}
Resumen
"Telebasura", "prensa sucia", "chismografía", "vidriera de miserias", son los términos utilizados para referir a los productos televisivos que tematizan el mundo del espectáculo y la vida cotidiana de las celebridades. Estas emisiones ocupan una porción significativa de la grilla de programación y son aquellas que obtienen los más altos índices de audiencia en promedio. Son habitualmente minusvalorados como objeto de estudio en el campo de la comunicación y la cultura por considerarlos un género menor, y -cuando son analizados- se los señala como espacios de banalización de la cultura y tergiversación de la actividad periodística. Los abordajes propues-

tos desde ciertas miradas feministas agregan a esta caracterización negativa, el sexismo y la reproducción de patrones hegemónicos de géneros y sexualidades como dimensiones clave en su estructura. Este artículo presenta un ejemplo del tipo de conexiones que pueden establecerse entre los sentidos que circulan a través de estas textualidades mediáticas y su contexto social de enunciación. A partir del análisis de algunos casos paradigmáticos, explora el modo en que el discurso sobre los derechos sexuales y de género se ha colado en los programas televisivos de chimentos a través de los relatos en primera persona de figuras relevantes del la farándula local.
\end{abstract}

Palabras clave: televisión; chimentos; Argentina; géneros; derechos.

\begin{abstract}
"Trash TV", "dirty press", "gossip", "stained glass of miseries"are the terms used to refer to television products that represents the world of entertainment and the daily lives of celebrities. These broadcasts occupy a significant portion of the programming grid and are those that get the highest ratings on average. They are usually underprivileged as an object of study in the field of communication and culture because they are considered a minor genre, andwhen analyzed-are seen as spaces of banalization of

culture and misrepresentation of journalistic activity. The approaches proposed from certain feminist perspectives add to this negative characterization, sexism and the reproduction of hegemonic patterns of genres and sexualities as key dimensions in their structure. This article presents an example of the type of connections that can be established between the meanings that circulate through these mediatic textualities and their social context of enunciation. From the analysis of some paradigmatic cases, it explores
\end{abstract}

Data de submissão: 2017-06-22. Data de aprovação: 2017-12-04.

A Revista Estudos em Comunicação é financiada por Fundos FEDER através do Programa Operacional Factores de Competitividade - COMPETE e por Fundos Nacionais através da FCT - Fundação para a Ciência e a Tecnologia no âmbito do projeto Comunicação, Filosofia e Humanidades (LabCom.IFP) UID/CCI/00661/2013.
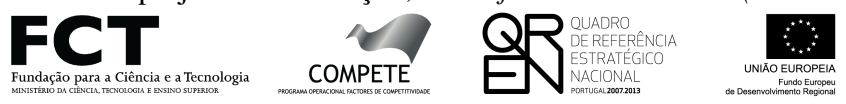

1) 
the way in which the discourse on sexual and gender rights has been cast in the gossip television programs through the first-person accounts of relevant figures in the local show business.

Keywords: television; gossip; Argentina; gender; wrights.

- Acá está la nueva LNNG... - ¿Y eso qué es? - "La Nueva Negra Graciela”, una mujer que se va a llevar el mundo por delante, sabélo, eh? Que no le importa el qué dirán, nada. Y sabé que nos vamos a divorciar pero que yo no soy ninguna boluda y que voy a mirar la letra chiquitita eh?, y que la división de bienes va a ser justa, la mitad y la mitad porque somos cuatro, cinco, conmigo cinco. - A ver negrita, ¿vos de dónde sacaste esas cosas, de dónde tanta información así me tirás, de la letra y todas esas cosas? - La nueva Negra Graciela aprende sabés, yo esas cosas absorbo, absorbo la información. ¿Qué te pensás? que miro todos los programas de la tarde y que no veo, no escucho las abogadas que dicen: "vos mirá, leé la letra chiquita" ¿eh? No, por eso, se terminó.

(Diálogo entre "El Bicho" y "La Negra Graciela", Educando a Nina, Underground, capítulo 127)

\section{Introducción}

667 TELEBASURA", "prensa sucia", "televisión rosa", "chismografía", "televisión del corazón",

1 "vidriera de miserias", son algunos de los términos utilizados para referir al conjunto de productos televisivos que tematizan el mundo del espectáculo y el entretenimiento, con especial interés en la vida cotidiana de las celebridades locales. Estas emisiones ocupan -en conjuntouna porción muy significativa de la grilla de programación y son aquellas que obtienen los más altos índices de audiencia en promedio. Son habitualmente desestimados o minusvalorados como objeto de estudio en el campo de la comunicación y la cultura por considerar al entretenimiento como un género menor, y -cuando son analizados- se los señala como espacios de banalización de la cultura y tergiversación de la actividad periodística. Los abordajes propuestos desde ciertas miradas feministas agregan a esta caracterización negativa, el sexismo y la reproducción de patrones hegemónicos de géneros y sexualidades como dimensiones clave en la estructura de este tipo de emisiones.

En Argentina estos programas tienen una tradición en la industria audiovisual y gráfica a la que nos referiremos más adelante que indica -cuanto menos- un interés sostenido por el género y por los temas relativos a la vida de las celebridades locales, tanto en lo referido a su vida artística como especialmente a su vida privada. Los programas a los que nos referimos en este trabajo tematizan la intimidad de las celebridades y los personajes del mundo artístico, hurgan en sus historias de vida, sus vínculos afectivos, familiares, los conflictos que mantienen con sus colegas del espectáculo entre otras dimensiones de la vida cotidiana de quienes protagonizan las notas -pautadas o robadas en una esquina- y ocupan los sillones de los estudios para dar cuenta de sí mismos. 
Este trabajo se inscribe en una investigación mayor cuyo propósito es describir y analizar las narrativas de los programas televisivos y revistas de actualidad sobre el espectáculo como espacios de construcción, reproducción y articulación de sentidos y normativas sobre las relaciones de género y sociosexuales. Se abordan en ella no sólo los discursos en torno a géneros y sexualidades allí construidos sino las rutinas profesionales que les dan lugar. Son de especial interés, las formas de concebir la intimidad, la verdad, el escándalo y el secreto y la relación que estas categorías establecen con la sexualidad y el género. Entendemos que los relatos de la vida cotidiana de las celebridades permiten indagar los imaginarios de una época en torno a las relaciones afectivas y sexuales, los roles e identidades de género y elecciones sexuales, la conyugalidad y extraconyugalidad, las modalidades de paternidad y maternidades, entre muchos otros.

Partimos de concebir a los medios masivos como tecnologías de género (de Lauretis, 1992) y sexualidades, que operan a partir de la puesta en marcha de estrategias de pedagogía moral, esto es, el despliegue -explícito o implícito- de un conjunto de valoraciones, clasificaciones y juicios sobre las conductas, que se proponen como reglas para la acción. En términos de Silverstone (2010) -los marcos de referencia propuestos por los medios para la aparición del otro que "definen de facto el espacio moral en el cual el otro se nos aparece y, al mismo tiempo, provocan (reclaman, delimitan) una respuesta moral equivalente en nosotros, la audiencia, en calidad de ciudadanos reales o potenciales" (:22). En la medida en que comprendemos el género y las sexualidades como dimensiones configurativas de la subjetividad y de las relaciones entre sujetos, nos interesan en particular los "símbolos culturales" y "los conceptos normativos" (Scott, 2000) que las hacen socialmente inteligibles (Butler, 1990). Por supuesto, estos símbolos y normativas son históricos y sólo pueden comprenderse desde un abordaje situado. En nuestro caso, esto implica no sólo una caracterización de la televisión contemporánea -sus retóricas y lógicas de producción- que permita comprender el lugar que los programas de espectáculo ocupan en la industria, sino también una contextualización de la trama social en la que esta televisión sucede, esto es, la agenda social y política con la que dialogan las representaciones que ésta pone en circulación.

Desde principios de 1990, la televisión argentina se caracterizó por seguir algunas tendencias de la industria a nivel internacional (Casseti y Odin, 1990; Eco, 1987). Se produjo el auge de la llamada telerrealidad cuyos formatos más clásicos son los talk y reality shows pero que incluyen también los programas periodísticos de investigación que proliferaron en los '90 y '2000, las narrativas ficcionales realistas, los programas de chimentos y espectáculos, los magazines y los formatos metatelevisivos. (Jost, 1997, Mondelo y Gaitán, 2002, Carlón, 2005). En términos temáticos y en relación con nuestro foco de interés, identificamos la tendencia a lo que algunos autores denominan pansexualismo televisivo o hipersexualización (Elizalde, 2009; Gill, 2012); esto es, la inclusión creciente de tópicos relativos a la sexualidad en los diversos géneros y formatos. Si bien esta inclusión no es novedosa en las industrias culturales que han hecho del sexo una mercancía altamente rentable, la especificidad de este período es que su inclusión atraviesa la grilla televisiva en forma horizontal y vertical. Podemos sostener entonces que, con énfasis a partir de los ' 90 , estas tendencias se articulan y conforman un continuo cultural mediático dedicado a la tematización de vínculos afectivos y sexuales y posiciones de género en clave realista. De este modo, el interés por los espacios de espectáculo televisivo y en particular por los magazines y programas de chimentos se funda no sólo en el lugar que fueron ocupando en la grilla televisiva a partir de 
la consolidación de la telerrealidad como marco de producción sino especialmente en el hecho de que son programas que se estructuran en torno del tratamiento de tópicos relativos a géneros y sexualidades.

Este hecho no es menor en relación a las transformaciones sociales recientes en el terreno de derechos sexuales y de géneros en Argentina. La última década estuvo signada por un proceso de ampliación de la ciudadanía sexual materializada en leyes y/o políticas públicas ${ }^{1}$. Los debates públicos y políticos en relación a estas transformaciones encontraron no sólo un espacio en la agenda mediática sino que comenzaron a ocupar paulatinamente la agenda de los programas televisivos de entretenimiento y espectáculo.

Es importante señalar además que la década de 2000 fue también un momento de profunda discusión sobre la función social de los medios masivos de comunicación y de cuestionamiento a las consecuencias de la concentración y la alianza de las grandes corporaciones mediáticas con actores económicos y políticos. Esto construyó un escenario de oportunidad para retomar uno de los objetivos que en el retorno a la democracia orientaba las demandas de las organizaciones sociales y de derechos humanos en materia de comunicación: reemplazar un decreto ley de la dictadura militar por una normativa que garantizara el derecho a la comunicación y democratizara la producción audiovisual. La sanción de la Ley de Servicios de Comunicación Audiovisual (26.522/09, en adelante LSCA) constituyó un hito insoslayable para cualquier abordaje de las mediatizaciones contemporáneas $^{2}$. En relación al tema que nos ocupa, la sanción de esta ley institucionalizó una concepción sobre la responsabilidad de los medios masivos en relación al tratamiento de cuestiones relativas a géneros y sexualidades que promueve la inclusión y garantiza la no discriminación ${ }^{3}$ (Boschiero, 2013).

En síntesis, lo que Pablo Semán (2015) definió como un estado deliberativo en cuestiones de género y sexualidades y que puede ser pensado como un signo del presente en Argentina encontró un terreno fértil en la industria televisiva que había ya estabilizado la telerrealidad y la sexualización como marcos de producción de sentido y que estaba discutiendo además su responsabilidad social en la protección de derechos. En este contexto, el análisis de la mediatización de géneros y sexualidades es relevante para conocer y comprender la producción de imaginarios sociosexuales (Sabsay, 2009) que operan como marcos de inteligibilidad para la tramitación simbólica de las transformaciones mencionadas.

1. Entre las leyes más relevantes se encuentran: la Ley de Educación sexual integral (26.150/06), de Prevención y Sanción de la Trata de Personas y Asistencia a sus Víctimas (26.364/08), de Protección integral para prevenir, sancionar y erradicar la violencia contra las mujeres (26.485/09), de Matrimonio igualitario (26.618/10), y de Identidad de género (26.743/12).

2. Cabe mencionar que esta ley fue parcialmente suspendida por decreto en diciembre de 2015 por el actual gobierno de la Alianza Cambiemos lo cual implica un grave retroceso para el ejercicio del derecho a la comunicación por parte de las audiencias y otros actores de la comunicación y la cultura en posiciones no dominantes.

3. Si bien excede el propósito de este trabajo, es importante señalar que las leyes y políticas de la última década incluida la LSCA incidieron también en las rutinas profesionales de los medios de modos más o menos explícitos, desde la adopción de indicaciones reglamentarias -por ejemplo, informar sobre líneas de atención a víctimas de violencia de género- hasta la revisión y discusión pública de ciertas prácticas discriminatorias en el devenir de la tarea. Veremos algunos ejemplos más adelante. 
En este artículo quisiera ofrecer un ejemplo del tipo de conexiones que pueden establecerse entre los sentidos que circulan a través de estas textualidades mediáticas y su contexto social de enunciación. A partir del análisis de algunos casos paradigmáticos, este trabajo explora el modo en que el discurso sobre los derechos sexuales y de género se ha colado en los programas televisivos de chimentos a través de los relatos en primera persona de figuras relevantes del la farándula local.

Para ello, se presenta primero una breve caracterización de los programas tomados como objeto de estudio. En segundo lugar, se desarrolla el análisis de lo que llamamos mediatización en clave de derechos, para concluir con una deriva epistemológica y metodológica en relación a por qué y cómo abordar estos espacios de enunciación televisiva en los estudios de comunicación, géneros y sexualidades.

\section{Indiscreciones}

Si bien no es el objetivo de este trabajo analizar la estructura comunicativa de los programas de chimentos y espectáculos -sus funciones, características temáticas y retóricas y sus estrategias enunciativas- en este apartado haremos una síntesis de sus aspectos más relevantes y un breve racconto de su surgimiento como género en Argentina para contextualizar el análisis que sigue.

Los programas televisivos sobre el espectáculo, conocidos como "programas de chimentos" surgen en Argentina como transposición audiovisual de las revistas dedicadas a la crítica del espectáculo televisivo -su programación y sus figuras- como La canción moderna, Radiolandia, TV Guía y Antena (Varela, 2010). También pueden identificarse como antecedentes las llamadas "columnas del corazón" en la prensa gráfica que pueden encontrarse prácticamente desde los inicios de la misma. En la actualidad se sigue verificando un campo de producción de información sobre el espectáculo que incluye las emisiones televisivas, las tradicionales revistas catalogadas como de "actualidad" -Gente, Caras, Semanario-, las revistas especializadas -Paparazzi, Pronto-; los portales web sobre chimentos y espectáculos -Primicias ya, Rating cero, Diario show, Chimenteros-; y ya en los últimos años las redes sociales -especialmente Twitter e Instagram- que funcionan también como productoras de información del espectáculo.

En relación específica a la televisión, en 1971 aparece en pantalla Radiolandia TV, el primer programa de espectáculos conducido por Luis "Lucho" Avilés en la pantalla de Canal 11. Este programa y su conductor se convertirían en los pioneros ${ }^{4}$ de un género que no hizo más que crecer y potenciarse en la industria televisiva.

Es importante señalar que la emergencia de estos productos audiovisuales coincide con el surgimiento de una "cultura de la celebridades" local. En un exhaustivo trabajo que recorre la historia de esta cultura, Alina Mazzaferro (2014) sostiene que -a diferencia de la cultura en torno del star system en Estados Unidos- en Argentina el interés por la vida y en menor medida la obra de las personalidades del espectáculo pone el foco especialmente en quienes participan de la industria televisiva. Volveremos sobre esto más adelante.

A Radiolandia TV le sucedieron varios programas conducidos por el propio "Lucho" Avilés que dieron lugar no sólo a nuevas figuras relevantes del formato, como Jorge Rial, sino también

4. "El pionero" fue, de hecho, el apodo que Luis Avilés se ganó en la televisión Argentina. 
a un nuevo estilo de tratamiento del espectáculo y los chismes en televisión. Indiscreciones, un programa emitido a partir de 1990 durante nueve años, sentó las bases de lo que hoy conocemos como programas de chimentos: un formato televisivo en el que la crítica del espectáculo cede casi por completo el terreno a la intimidad de sus personalidades y que comenzará paulatinamente a incluir el "escándalo" como uno de los ejes articuladores de las emisiones. Indiscreciones incorporó columnistas dando pie a lo que luego se estabilizaría como esquema de elenco en piso: un/a o dos conductoras/es y varios panelistas. Desde mediados de los '90 los chimentos se instalan en la televisión argentina en los canales de aire de forma ininterrumpida y comienzan a ocupar horas de la grilla de un modo múltiple: programas en todos los canales, varios programas en algunos de ellos, segmentos de chimentos en los noticieros y magazines, emisiones en la televisión por cable y en los canales de noticias ${ }^{5}$. El programa que lidera desde hace dieciséis años el mercado del chimento en Argentina es Intrusos en el espectáculo, no sólo por su permanencia en pantalla sino por ser el espacio en el que surgen y se forman futuras/os conductoras/es y figuras mediáticas.

Más tarde se incorporará a la televisión un formato híbrido entre el viejo magazine televisivo, el programa de chimentos y el informativo que funciona en general como un espacio de conversación sobre la propia televisión y retoma de cada uno de estos géneros sus aspectos centrales. Pueden incluir segmentos de cocina, espacios de información de actualidad -repaso de la información del día-, temas de interés general, y amplias secciones de chimentos con panelistas y entrevistas en piso. En la actualidad se encuentran en pantalla programas como Desayuno Americano, El Diario de Mariana o Morfi y ha habido algunos que marcaron tendencia como Movete con Georgina y Movete luego conducido por Carmen Barbieri y el más reciente AM (Antes del Mediodía) emitido hasta 2016 por Telefé.

A estas transformaciones sucedidas durante las cuatro décadas que los chimentos llevan en pantalla en Argentina hay que sumar dos relevantes para el tema de este trabajo: en primer lugar, a partir de los 2000 se incorpora en los programas de chimentos el tratamiento de temas de actualidad general, en particular acontecimientos de relevancia social con alto impacto en la agenda pública o política. En segundo lugar, aparecen en pantalla un conjunto de programas de espectáculos "satélites" (Carlón, 2005) dependientes del show televisivo de más altos índices de audiencia local, Showmatch. Este certamen de baile se emite desde 2005 en horario central por Canal 13 y está conducido por uno de los personajes más influyentes de la industria de la televisión argentina -Marcelo Tinelli- se convirtió en un articulador clave de la producción televisiva y un marcador de agenda de los programas de espectáculos y chimentos en general ${ }^{6}$. Podemos decir que la actualidad del espectáculo se encuentra en gran medida pautada por los acontecimientos sucedidos en Showmatch o en relación a sus figuras.

También es importante señalar que para la década de 2000 estaban desapareciendo los antiguos formatos de debate político emitidos por televisión abierta, algunos de los programas pasaron a emitirse por cable y su lugar en la grilla abierta fue ocupado por entretenimiento y ficción (Justo von Lurzer y Moglia, 2008). El debate político en los canales de aire quedó restringido a los espacios informativos clásicos -noticieros-, los programas periodísticos de investigación que de-

5. Para un desarrollo de la historia reciente de estos programas puede consultarse Alvarado (2014).

6. Excede los objetivos de este trabajo pero es necesario señalar que la figura de Marcelo Tinelli es relevante por fuera de la industria televisiva en su calidad de empresario y dirigente deportivo. 
saparecieron de la pantalla para fines de 2000 y algunos programas que incluían humor político -como CQC o Televisión Registrada-. Ya en 2009 aparecen en televisión abierta algunas variaciones de formato que vuelven a poner en escena el debate político en televisión y cuyos ejemplos paradigmáticos son 6,7,8, Intratables, Duro de Domar, Animales sueltos. ${ }^{7}$ Algunos de ellos fueron evolucionando hacia los magazines de media noche o "late shows" (Cáceres, 2010).

La especificidad, entonces, de los programas de chimentos clásicos y de los segmentos de chimentos en otros formatos es que presentan un breve resumen de la actualidad del mundo del espectáculo y profundizan en los rumores, escándalos y conflictos de personalidades de la farándula local. El formato, como dijimos, cuenta con un/a conductor/a y un grupo de panelistas y se incluyen los cronistas que se ocupan de hacer las notas furtivas y entrevistas en exteriores. Los contenidos combinan las notas grabadas que salen al aire con una breve presentación por parte del/la conductor/a o las/os panelistas y comentarios y discusión posterior en piso con entrevistas en vivo (generalmente en piso pero también se realizan en exteriores) a personalidades implicadas en alguno de los temas del día.

En suma, las transformaciones que hemos ido mencionando son el correlato de cambios más amplios en el discurso televisivo en Argentina que hicieron de la programación un espacio de cotidianeidad y contacto, y de los programas de chimentos en particular expresiones de lo que Sibilia (2008) conceptualizó como intimidad pública. De este modo, en los programas de chimentos se articulan el giro biográfico (Arfuch, 2002), la rentabilidad de la telerrealidad en la industria del entretenimiento televisivo y la utilización de viejas y probadas retóricas populares-masivas: la confesión, la búsqueda de la verdad, la revelación de un secreto, la burla, la confrontación y el conflicto personal son algunas de las más relevantes en estos formatos (Barbero, 1992; Rincón, 2015; Cáceres, 2010).

Alertas sobre el objeto: Basura sexista.

En relación a los análisis comunicacionales y culturales, los espacios de espectáculo televisivo y especialmente los programas de chimentos han sido objetos desplazados, desestimados o superficialmente criticados por banales. La práctica profesional de conductoras/es y cronistas se encuentra des jerarquizada y cuando es incluida en el campo periodístico es considerada un periodismo de segunda (Soto, 2005; Ferrero, 2008). Podríamos pensar que esta desvalorización de los programas de espectáculo se inscribe en una jerarquización de los mundos de la televisión (Jost, 1997) que ha hecho prevalecer el espacio de la información por sobre el de la ficción y el entretenimiento. Esta diferenciación en mundos simbólicos televisivos que dio lugar a la clásica distinción entre funciones -informar, educar y entretener- ha implicado el cuestionamiento sistemático al

7. Intratables y Animales sueltos son dos programas que permiten pensar desplazamientos entre el interés general, el espectáculo y la política: en el primer caso, un programa que se desprendió de Infama-formato clásico de chimentos de la tarde de América- y, con el mismo conductor que durante varios años hizo ambas emisiones diarias- invirtió el foco de la información para pasar a tratar los temas de agenda informativa y política de cada día. Puede pensarse que, con fuerza desde 2015, se convirtió en el ágora política de la televisión de aire. En un sentido similar pero dentro del propio programa, Animales sueltos pasó de ser un magazine de medianoche con entrevistados del mundo de la farándula en piso, a incorporar luego un primer segmento con una entrevista uno a uno entre Alejandro Fantino, su conductor, y alguna personalidad entre las que se incluían políticos y funcionarios públicos, a -finalmente y hasta hoy- constituirse en un formato similar a un antiguo programa llamado Polémica en el Bar, en el que varios periodistas, intelectuales y personajes de la cultura discuten la agenda política e informativa del día. 
entretenimiento como una función y un espacio simbólico que debería ceder protagonismo a la información y en segundo plano a la ficción y que -sin embargo- predomina en los canales comerciales. Si bien podría objetarse que estas funciones y mundos son ya más difíciles de distinguir con claridad en una televisión caracterizada por la hibridación genérica y por el predominio de la telerrealidad, podemos observar la permanencia de estos imaginarios no sólo en los análisis académicos sino también entre las audiencias.

Tal como mencionamos en el apartado anterior, los programas de chimentos parecen ser un desprendimiento, una deformación más bien, del antiguo periodismo de espectáculos. Gastón Cingolani (2006) sostiene que estos programas se organizan como programas periodísticos en la medida en que se emiten en directo, producen información y "el universo del que se ocupan está temporalmente circunscripto por el concepto de actualidad. De hecho, estos programas suelen tener una salida diaria y la renovación de la información está sujeta a esta frecuencia" (:16). Sin embargo, críticos como Sirvén, sostienen que "antes cuando uno hablaba de periodismo de espectáculo suponía que iba a haber alguna entrevista con algún actor o productor o director y que también podía llegar a haber algún tipo de información de la llamada 'prensa del corazón'. En los últimos años, involucionó eso esencialmente en la televisión abierta y periodismo de espectáculo es una especie de show en el que vedettes, semi vedettes, aspirantes a vedettes, mediáticos, artistuelos y alguna que otra figura reconocida hablan y patalean y se insultan sobre cuestiones incomprobables de su privacidad" 8 .

Podríamos pensar que es la retórica del escándalo lo que ha puesto en cuestión la calidad informativa y la función comunicativa de estos programas, sin embargo, en tiempos de infoentretenimiento resulta difícil imaginar espacios periodísticos de amplio alcance en términos de audiencia y repercusión en la agenda pública que no espectacularicen o escandalicen la vida social. Por no mencionar aquellas teorías que sostienen que la vida social como un todo se produce desde hace décadas como "espectáculo" (Debord, 1976). El conflicto narrativo como matriz de producción de sentido es ya una constante en la industria televisiva y los tópicos abordados en los programas de chimentos estructuran, por ejemplo, buena parte de las ficciones literarias, cinematográficas y teatrales: relaciones afectivas, sexualidad, maternidad, los vínculos extraconyugales, los dramas identitarios, entre muchos otros. Sin embargo, puestos en escena en programas de chimentos estos contenidos son periodística, ética y estéticamente cuestionados y se tornan irrelevantes, íntimos y de mal gusto (Soto, 2005; Ferrero, 2008; Díaz, 2004; Cáceres, 2000). Dejo planteada para futuros trabajos la pregunta por las implicancias que tiene, entonces, que esos tópicos sean tratados en una matriz realista, ¿cómo modifica el estatus de lo dicho el hecho de que esté encarnado en sujetos de fama o reputación pública?

De este modo y como hemos mencionado al inicio, la televisión basura, la prensa rosa, es pensada desde un marco interpretativo que señala los mecanismos de degradación del periodismo, las prácticas éticamente cuestionables, en suma la ocupación del espectro audiovisual con contenidos y tratamientos que empobrecen los universos culturales de sus audiencias. Este trabajo se distancia de estas perspectivas para plantear la posibilidad de leer los programas televisivos de

8. Entrevista a Pablo Sirvén en el programa "En el medio", Temporada II, Episodio 5. Canal Encuentro, Argentina. Disponible en http://encuentro.gob.ar/programas/serie/8103/1482?temporada=2 
espectáculos y de chimentos como sitios en los que se instalan y discuten tópicos sobre géneros y sexualidades, se produce y difunde información socialmente relevante y -en el último tiempo- se lo hace además desde una perspectiva de derechos.

Esto nos lleva a la segunda crítica habitualmente formulada a estos programas; no son sólo "basura" sino que son "basura sexista". Los estudios feministas en comunicación y género tienen ya una larga tradición cuyo inicio puede ubicarse a fines de los años 1960 con los trabajos pioneros sobre "imágenes de las mujeres" (Hollows, 2000) que se detenían especialmente en la reproducción de estereotipos sexistas en los contenidos de los medios de comunicación. Estos primeros trabajos sentaron las bases de una perspectiva sobre la cultura de masas y los medios de comunicación que aún hoy sigue operando en muchísimos abordajes de objetos culturales y comunicacionales y que entiende que éstos son nocivos para las mujeres que los consumen en la medida en que contribuyen a reproducir las condiciones de desigualdad de género que las subalternizan. Fueron los análisis llevados adelante desde el Centro de Estudios Culturales Contemporáneos británico (Radway, 1991; McRobbie, 1998, entre otras) aquellos que comenzaron a discutir esta visión y que permitieron desarrollar líneas de trabajo que atendieran no sólo a los múltiples y contradictorios vínculos que las audiencias establecen con sus consumos culturales sino también a las tensiones y contradicciones que los propios productos presentan en sus configuraciones retóricas y temáticas (Hall, 1981; Best, 1997; Barbero, 1986).

Los programas de chimentos, como la novela rosa, las revistas femeninas o la canción romántica han sido rápidamente diagnosticados como transmisores de una ideología patriarcal que lo infecta todo a su paso, particularmente a las mujeres. Convertidos, entre otros males, en vehículos de la ideología del amor romántico y modelos de belleza inalcanzables salvo a costa de poner en juego la propia integridad física o entregarse a las manos de las tecnologías estéticas del mercado, se pierde de vista la complejidad que estos productos culturales proponen y habilitan. Trabajos como los ya citados y algunos más recientes como el clásico de Lila Abu Lughod (1997), o a nivel local los de Carolina Spataro (2011) y Mayra Alvarado (2014) ponen en jaque las visiones reduccionistas y pesimistas sobre estos productos y la relación que las audiencias establecen con ellos.

Es importante aclarar que tanto en los productos culturales que hemos mencionado como en los programas de televisión que nos ocupan aquí pueden, efectivamente, reconocerse las dimensiones y rasgos señalados por la crítica cultural feminista hegemónica: son espacios reproductores de un orden sexista, despliegan formas de violencia simbólica hacia las mujeres y refuerzan estereotipos discriminatorios. Pero esto no es lo único que hacen y, mucho menos, lo único que habilitan.

Los estudios sobre celebridades vienen señalando la relevancia de estos productos culturales para el análisis de las sociedades contemporáneas. Graeme Turner (2010) indica que si bien estos estudios se han desarrollado atendiendo a las representaciones y, en menor medida, a la relación de las audiencias con ellos, su relevancia reside en la conceptualización de la "celebridad" 9 como una "formación cultural que tiene una función social" (:14, traducción propia). El autor sostiene que la ““celebridad' no sólo está implicada en la producción de comunidades como los grupos de

9. Entendemos que el autor refiere a la "celebridad" no sólo como un status de sujeto sino como una condición, lo célebre como aquello que concita notoriedad pública y en torno de lo que se expresan opiniones y valores. 
fans o subculturas, no sólo genera una cultura de la celebridad y redes sociales, también participa del campo de expectativas que muchos, especialmente los jóvenes tienen de la vida cotidiana" (:14). En un sentido similar, puede pensarse que la celebridad también es una formación cultural en la que se procesan transformaciones sociales y demandas de derechos que alcanzan -desde un espacio de identificación y sensibilidad- a las audiencias.

\section{Farándula y política, nada nuevo bajo el sol}

Es importante señalar que ni el lugar de las figuras televisivas como referentes sociales ni la relación que éstas han mantenido con ciertos partidos políticos, movimientos sociales o con el posicionamiento en relación a cuestiones de orden público resulta novedoso (Marshall, 1997; Benett, 2011). Como hemos mencionado, en Argentina surge en la década de 1960 estrechamente ligada a la televisión un sistema de famosas/os. (Mazzaferro, 2014). La/el famosa/o, "no sólo era un actor o actriz, sino cualquier figura que apareciera por televisión. Su éxito se sostenía por su personalidad o carisma; la formación o el talento ya no eran requisitos indispensables para la fama televisiva. Ascendía vertiginosamente en el campo del espectáculo; su descenso o desaparición podía ser igualmente instantáneo. Su vida privada proveía los contenidos que el medio requería, alimentando su popularidad. La desmesura de sus ganancias, su amplia capacidad de colocar productos en el mercado cultural y una importante cantidad de seguidores fanáticos eran la 'prueba' de su carácter 'famoso'. Mantenía su estatuto mientras producía discurso mediático (intra o extratelevisivo). Este último podía ser a favor o en contra del 'famoso' (podía ser una alabanza o una crítica); la 'mala prensa' era también una forma de obtener la fama y posicionarse en el espectáculo" (:206).

Su condición de famosa/o transformaba su palabra en un discurso con relevancia y legitimidad social. Los ya citados estudios sobre celebridades, poco desarrollados en Argentina pero con una tradición en las academias anglosajonas, se han ocupado de problematizar el valor social del discurso de las celebridades y las resonancias e incluso incidencia que éste tiene en cuestiones de orden público. Resulta sencillo traer a la mente celebridades internacionales y de cada uno de nuestros países formando parte de campañas de bien público, propagandas de acciones de gobierno o actos de militancia partidaria. También se ha vuelto frecuente el uso de los espacios en premiaciones u otros eventos del mundo del espectáculo para pronunciarse en relación a temas de coyuntura política y social local e internacional: por mencionar sólo algunos de los más recientes, la intervención en el Festival de Cannes de los actores brasileros con carteles que decían "Fora Temer" como parte de la campaña contra el golpe de estado perpetrado por el actual titular del ejecutivo de ese país, Michel Temer; la intervención de la actriz argentina Dolores Fonzi en los premios locales Platino en los que alzó un cartel que decía "Libertad para Belén" y se pronunció por los derechos de las mujeres y la libertad de elegir sobre sus cuerpos en relación al caso de la joven que estuvo detenida por un aborto espontáneo en la provincia de Tucumán durante 2016; o el discurso de Madonna en los premios de la revista Billboard en los que se explayó durante poco más de diez minutos en relación a la desigualdad de las mujeres en la industria de la música, las violencias de las que somos objeto cotidianamente, la incidencia de los patrones de belleza en nuestras vidas entre muchas otras cuestiones. Por supuesto, no ha sido menor el lugar de las 
redes sociales en la viralización de estos fragmentos discursivos. Mientras termino de escribir este trabajo uno de los videos con más reproducciones es el discurso dado por Meryl Streep en la entrega de los premios Globo de Oro en Estados Unidos y la respuesta que el actual presidente de ese país -Donald Trump- publicara en Twitter ${ }^{10}$.

Tampoco es novedoso el tratamiento de la vida privada y la cotidianeidad de los famosos, no sólo porque -como hemos dicho- es de algún modo el germen de la cultura de la celebridad local sino porque la televisión en general (y podríamos pensarlo incluso como un clima de época que excedió en mucho a los propios medios masivos de comunicación) fue tendiendo a la conformación de espacios de puesta en publicidad de la intimidad. La telerrealidad ha sido uno de los espacios privilegiados para esta transformación cultural antes y luego en simultáneo con la expansión del uso de las redes sociales. La televisión del contacto y la cotidianeidad dio lugar a la aparición de los "donnadies" (Dieter Rath, 1992) como protagonistas de la programación. Los talk y reality shows fueron incubadoras de una nueva categoría de actor televisivo "el mediático", un producto intratelevisivo que es puesto a circular y a producir contenido sobre sí mismo o a producirse a sí mismo como contenido en los diferentes formatos disponibles (chimentos, ficciones, entretenimiento). La televisión del contacto profundiza la identificación como regla y para ello es necesario que ecualice las experiencias: así como los nadies pueden ser ahora protagonistas porque sus vidas tienen valor en la pantalla, las celebridades experimentan las vicisitudes cotidianas de los públicos anónimos ${ }^{11}$.

Podríamos pensar además, que luego de la crisis de 2001, Argentina atravesó una década larga de recuperación económica y especialmente de recuperación social y política: la desconfianza en la clase dirigente traducida en el lema "que se vayan todos" cedió terreno a renovadas disputas en torno del lugar del Estado, de la representación política y las acciones de demanda de derechos. Este nuevo clima político se tradujo en la industria televisiva de modos múltiples: la producción de contenidos que tematizaron tópicos sociales, la aparición de lo que provisoriamente hemos denominado más arriba "magazines políticos" o "late shows políticos", el posicionamiento político partidario de personalidades del espectáculo y su activismo en relación a la demanda de derechos específicos.

Como ya mencionamos, el vínculo entre política y celebridades no es novedoso ni en Argentina ni en otros países. Tampoco lo es la inclusión de temas de interés general o social en los programas de espectáculos y chimentos. Puede rastrearse además en la historia de la televisión reciente el uso táctico que muchos colectivos han hecho en los programas de alto rating para instalar ciertos debates o difundir ciertos temas. La mesa de Mirtha Legrand o el living de Susana

10. Tweet de Donald Trump al día siguiente del discurso: "Meryl Streep, una de las actrices más sobrevaloradas de Hollywood, no me conoce pero me atacó anoche en los Globos de Oro. Ella es una..."(9 de enero de 2017)

11. Es emblemático el cartel que se viralizó hace poco tiempo en relación a la infidelidad del actor Benjamín Vicuña en su relación con la modelo Carolina "Pampita" Ardohain y que decía "Amiga, relájate y disfrutá de las cosas buenas de la vida. Si no estás depilada, no importa! Si las raíces de tu pelo tienen varios centímetros, no importa! Si tenés unos kilitos de más, más celulitis, más arañitas, no importa! Disfrutá lo bueno, la cerveza helada y la picada con amigas. Andá a la pileta como se te cante el culo, disfrutá de tu cuerpo, lo que te haga feliz. Total, la cagaron a Pampita! A Pampita! Al pedo tanto sacrificio" 
Gimenez ${ }^{12}$ han funcionado como espacios privilegiados a los que paulatinamente fueron incorporándose los programas de chimentos y magazines de la tarde. En relación a los derechos del campo de géneros y sexualidades, el movimiento LGBT ha tenido una estrategia comunicacional de diálogo y presencia pública constante en la programación televisiva. Carlos Jáuregui, Ilse Fuskova, más tarde Alex Freire, María Rachid, entre muchos otras/os referentes del activismo se transformaron en figuras de visibilidad pública también en los espacios de entretenimiento. Lo que me interesa plantear entonces son dos matices: el pasaje del activista mediático al famoso militante y la adopción de una perspectiva y/o un léxico de derechos para el tratamiento de ciertos tópicos relativos a géneros y sexualidades. En el primer caso, porque si durante los ' $80 \mathrm{~s} \mathrm{y} \mathrm{'} 90 \mathrm{~s}$ eran centralmente las/os activistas quienes se sentaban en los livings o en las mesas de los estudios de televisión y visibilizaban las demandas de sus colectivos, en los últimos años han sido las/os famosos quienes se han posicionado como sujetos de esos derechos.

En segundo lugar porque los habituales relatos de vida de las/os famosas/os que organizan al agenda de los programas de chimentos comenzaron a ser mediatizados en un marco de demanda de derechos; es decir, una experiencia personal de alguna celebridad que ponía en agenda un problema social o una demanda: fertilización asistida, consumo de drogas, derechos de filiación, incumplimiento de cuotas alimentarias, violencia de género, entre otras. En estas situaciones, el testimonio de la/el famosa/o pone en escena un problema social que no necesariamente está en agenda pública pero que puede tener repercusión social. En otros casos, el/la famoso/a se suma a un movimiento de demanda existente y hace pública su exigencia posicionándose como sujeto de ese derecho: matrimonio igualitario, identidad de género, violencia de género, aborto, entre otras. Aquí el testimonio del/la famoso/a funciona como articulador de un debate público de actualidad y puede pensarse como un modo de incidencia política deliberado en procesos de debate parlamentario. En la memoria social argentina sobre la discusión legislativa en torno del Matrimonio Igualitario quedará grabado el papel de figuras del espectáculo como José "Pepe" Cibrián Campoy y la pregunta incómoda en la mesa de Mirtha Legrand cuando se discutía la posibilidad de adopción por parte de parejas del mismo sexo: “¿Pepe o calle?” 13, así como el recitado del poema de su autoría en homenaje a Federico García Lorca en la Legislatura y su grito final "¡Marica!”.

En un sentido similar puede pensarse el lugar que ocuparon personalidades de los medios de comunicación y la cultura en el momento de mayor ebullición social en relación a la violencia de género. El movimiento NiUnaMenos surgió por iniciativa de un grupo de periodistas, escritoras, intelectuales y artistas y se multiplicó inicialmente a través de las redes sociales. El acto central luego de la primera manifestación masiva el 3 de Junio de 2015 fue conducido por una reconocida escritora y dibujante -Maitena- y la pareja protagónica de la tira diaria de mayor rating en la televisión local en ese año -Paola Barrientos y Juan Minujín, protagonistas de Viudas e hijos del Rock and Roll, una producción de Underground que se emitía por Telefé en horario central.

12. Mirta y Susana son las conductoras de televisión más reconocidas a nivel local. Ambas conducen desde hace décadas programas de alta audiencia y repercusión social y, con estilos bien diferenciados, se han ganado el título de "divas" de la farándula argentina.

13. www.youtube.com/watch?v=RJo5kEwUNkU. Recuperado el 28 de marzo de 2017. 


\section{Tramitación simbólica de las transformaciones sociales: lo personal es político}

En este apartado ejemplificaré, a partir del análisis de una serie de ejemplos paradigmáticos ${ }^{14}$, los matices que identificáramos antes -los famosos como sujetos de derechos y la mediatización de géneros y sexualidades en clave de derechos-. Para dejar planteado el modo en que propongo aproximarnos a los contenidos televisivos, he tomado algunos temas que en los últimos años formaron parte de la agenda de debate público y político -matrimonio igualitario, identidad de género, violencia de género, fertilización asistida- y cuya mediatización permite caracterizar el modo en que concebimos aquí los programas de chimentos y espectáculos.

Trabajaremos en lo que sigue con algunos fragmentos de emisiones recientes en televisión abierta argentina -tanto en programas de chimentos como en magazines de espectáculos- con el objetivo de caracterizar cuatro dimensiones de este tipo de programas que echan luz sobre sus funciones sociales menos tematizadas: producir y difundir información socialmente relevante; constituirse en escenario de debate púbico y enunciación de demandas de derecho; generar identificación y servir a la comunidad; discutir el rol de los medios y las/os comunicadoras/es sociales.

Es importante señalar el contexto de emisión de los ejemplos a los que recurriré en esta sección. Algunos de ellos fueron participaciones de figuras del espectáculo local en los programas objeto de este trabajo en el contexto explícito de debate y activismo en torno de alguna ley -Matrimonio igualitario, Identidad de género, Fertilización Asistida, Ley de emergencia contra la Violencia de género-. Otros se vinculan con el reclamo de la aplicación de las normativas vigentes. Si bien excede los objetivos de este trabajo, es importante tener en cuenta el momento de enunciación de las demandas para poder observar los matices y desplazamientos que se producen en el discurso (lo decible) y la acción política entre momentos de incidencia directa y ebullición pública y momentos de institucionalización y repliegue del debate.

Todos los ejemplos seleccionados -tomados in extenso- condensan las cuatro dimensiones que señalaba al inicio de este apartado, sin embargo, he decidido fragmentarlos de modo de poder focalizar en cada una de ellas por separado.

\section{“Cinco mujeres mueren por semana en Argentina". Producir y difundir información social- mente relevante}

La movilización social en torno a la violencia de género ha crecido significativamente en los últimos años en Argentina y ha encontrado incluso un punto de anclaje fuerte en el movimiento conocido como NiUnaMenos, ya mencionado en este trabajo. Si bien en 2009 se promulgó la Ley de Protección integral para prevenir, sancionar y erradicar la violencia contra las mujeres (26.485), la ausencia de políticas de Estado en la materia y la alta tasa de casos de violencia de género y femicidios generaron un contexto de sostenida y creciente demanda en torno de la necesidad de acciones urgentes. Este clima fue retomado en los espacios de chimentos y espectáculo de dos modos diferentes: a partir del tratamiento de un acontecimiento de interés público -un acto de violencia o femicidio de alguna mujer del común- o del relato en primera persona de situaciones de violencia por parte de mujeres del mundo del espectáculo.

14. Expresan con claridad las tendencias que pueden observarse en otros ejemplos del mismo período. 
El primer fragmento forma parte de una entrevista que el conductor del programa de chimentos más reconocido de Argentina-Intrusos- le hiciera a la cantante y actriz Laura Miller en el marco de la campaña por la declaración de la emergencia en violencia de género en el año 2015.

La entrevista se inicia con el relato de Jorge Rial, el conductor, que aclara que la actriz y cantante acaba de ser nuevamente amenazada por su novio. Mientras la cámara enfoca a la Laura Miller notablemente conmovida y la musicalización crea un clima de dramatismo, Rial dice "tiene el botón antipánico al lado de ella, lo tiene ahí al lado de la mesita, quiero decir, anda con ese botón antipánico las 24 horas... por miedo".

(Laura Miller) "Por miedo, porque me lo dieron a raíz de una denuncia que hice en la comisaría 45 de Devoto por hostigamiento, acoso y amenazas y está en el juzgado 28. La lleva a cargo el fiscal Perel. Ahora el 12 de mayo tengo que ir nuevamente a hacer una nueva declaración y obviamente a adjuntar esta nueva amenaza directa a la causa porque todo lo que sucede se va adjuntando al expediente. Esto lo hago porque es algo que viví, es algo que me pasó, que fue una tortura que viví durante dos años y todos mis amigos que vivieron conmigo lo que viví bueno nos juntamos e hicimos el video de Invencible y lo empecé a presentar y me empecé a sentar en todos los programas para hablar para ayudar, para concientizar a la gente de lo que es la violencia de género. No lo nombro con nombre y apellido porque no puedo hasta que un juez no dictamine la sentencia pero él sabe que estoy contando esta situación y... y es terrible, es terrible esto que estamos viviendo en el mundo es una cosa que no tiene fin, Jorge, no se puede creer. Yo estoy indignada porque desde que hice esto público hay muchas mujeres que me están escribiendo todos los días, por Facebook... por... yo ayer hablé con una señora que le prendieron fuego a la hija, el marido le prendió fuego y delante de sus nenes, y un montón de casos que conocemos. Cinco mujeres mueren por semana en Argentina. Hay un femicidio en la Argentina que cada vez crece más. Entonces yo estoy haciendo todo esto porque acá tiene que haber una ley de emergencia contra la violencia de género que nadie la quiere votar, nadie le quiere dar una entidad" 15 (las cursivas son nuestras).

Mientras ella desarrolla el relato en el zócalo puede leerse "Para denunciar violencia de género. Llamar al 144 las 24hs".

En este primer fragmento de entrevista aparece un recorrido que va del hecho personal -la denuncia de violencia- a la demanda social -caracterización de una problemática y exigencia de una ley-, pasando por la producción de información -los procedimientos, las estadísticas- y la utilidad e identificación -concientización y construcción de un nosotros-. La entrevista continúa con la descripción de situaciones experimentadas por la actriz y cantante a partir de las que también se aporta información relativa a la violencia de género: sus modalidades -frente a la afirmación del conductor de que las mujeres suelen tardar en denunciar por miedo ella sostiene "Porque saben que no les dan bola o porque no tienen cómo mantenerse porque también hay una violencia económica dentro de la violencia de género, abarca la física, la psicológica, la económica, la

15. https://www.youtube.com/watch?v=oHunO-6h5YY. Recuperado el 28 de marzo de 2017. 
sexual", sus consecuencias -"porque la violencia psicológica te trae trastornos de la alimentación, ataques de pánico, depresión, ansiedad, stress postraumático y te puede llevar al suicidio"-, entre otras cuestiones. La crónica de los hechos se abstrae por momentos de lo personal y se desplaza hacia la caracterización de un perfil psicológico "el violento", la "víctima de violencia" o hacia un tipo penal o un modo de acción o relación interpersonal o social -tipificación de las posiciones posibles del agresor, la agredida, las fuerzas de seguridad, la dirigencia política, entre otras-,

"yo recuerdo, cuando Monzón mató a Alicia Muñiz ${ }^{16}$, a su mamá contando cómo Alicia iba a la comisaría de Villa Urquiza a denunciar que Monzón le pegaba y ¿qué hacían los policías?, se le reían en la cara. Porque nunca se le creyó a la mujer. Ahora hay comisarías de la mujer... [Laura Miller lo interrumpe: 'pero no son suficientes...] no, claro... lo que estoy diciendo es la diferencia ahora hay comisarías de la mujer, poquitas, botón antipánico... antes se te reían y te mandaban a casa de vuelta”. (Jorge Rial)

Luego, Laura Miller continúa desarrollando otros aspectos más directamente vinculados con la inacción del Estado y la clase política en relación a las situaciones de violencia que atraviesan las mujeres.

Al día siguiente, en el magazine de espectáculos Desayuno emitido también por América TV y conducido por Pamela David, se generó un living de debate del que participaron un periodista del staff habitual, la entonces diputada nacional -Vilma Ripoll-, una diseñadora de modas que lleva adelante una campaña de concientización contra la violencia, una vedette que denunció públicamente a su ex pareja por violencia de género -Mónica Farro- y una mujer "Noelia", que estaba viviendo en ese momento una situación de violencia que era de conocimiento público. Nuevamente los zócalos que acompañaron el segmento aportaban información relevante sobre el tema y oscilaban entre el anclaje social o individual del problema: "en Argentina muere una mujer cada 32 horas" "Testimonios de víctimas de femicidio. Dramáticos relatos sobre violencia de género".

En este caso es el periodista el que, luego de escuchar el relato pormenorizado de la situación de violencia de Noelia, pregunta a la diputada por la responsabilidad del Estado:

“¿Hay algo más que el Estado tendría que hacer? ¿Qué es lo que hay que hacer? ¿Hay una estructura que contenga a la mamá que tiene la valentía de denunciar y que no sabe dónde ir? (Luis Novaresio). (Vilma Ripoll) Nosotros decimos tiene que haber una ley, que en provincia ya se votó pero que no se votó la prórroga, pero tiene que haber presupuesto. La Ciudad de Buenos Aires, que es la ciudad con más presupuesto de todo el país, destina de su presupuesto el 0,07 por ciento anual al problema de violencia. Entonces no hay refugios que las contengan en el primer momento, no hay subsidios que les puedan permitir mudarse y tener de qué vivir al principio. (...) Tiene que haber casas refugio, hay una en la Ciudad de Buenos Aires para tres millones de habitantes y hay cuatro en la Provincia para quince millones de habitantes, la mitad mujeres. Entonces olvídense"

16. Refiere al boxeador argentino Carlos Monzón que en el año 1989 fue condenado a 11 años de prisión por haber golpeado, estrangulado y arrojado por un balcón a su entonces pareja, Alicia Muñiz. 
Estas afirmaciones son recuperadas por la vedette Mónica Farro para contar las razones por las que ella misma no había denunciado a su agresor, en la medida en que era uno de los productores del programa en el que ella trabajaba -Showmatch- y temía quedarse sin ingresos económicos y sin un lugar donde vivir. Nuevamente aparece aquí el tránsito entre la problemática social y el caso y se entraman los relatos de las celebridades con los posicionamientos políticos.

El segmento se cierra con una intervención de la diputada Ripoll que es retomada y prácticamente citada textual por el periodista Novaresio que, una vez más, da cuenta de la producción de datos e información y de los cursos de acción que pueden tomarse frente a ciertas situaciones. Sostiene la diputada:

"Si escuchamos que al lado de nuestra casa hay un hecho de violencia no nos quedemos callados. Busquemos en las organizaciones de mujeres. La oficina de violencia de la Corte que queda acá en Lavalle al 1500. Y quiero denunciar la actitud machista y patriarcal de la justicia y la policía, hasta en las comisarías de la mujer vos vas a denunciar y te quieren hacer decir qué te pasa delante de todos, si no aparecés con la cabeza partida no te quieren tomar la denuncia. Cuando una mujer desaparece te dicen que son 48 horas. ¡Mentira! Tienen que salir a buscarla inmediatamente.

(Luis Novaresio) Quiero retomar algo muy importante que acaba de decir Vilma que es un ejemplo, cuando hablamos de la política, Vilma es la política y es bien distinta a la mayoría. No existen las 48 horas para ninguna denuncia de pérdida de persona, si no te toman la denuncia, a la fiscalía, si no al juez de turno y si no recurrí a Vilma o a algún medio pero cuando desaparece una persona, una mujer, hay que recurrir rápidamente al Estado." 17

Este mismo tratamiento de los temas puede encontrarse en relación a otros tópicos como identidad de género o fertilización asistida. En este último caso, se registraron una gran cantidad de informes y entrevistas a famosas/os que habían utilizado técnicas de reproducción asistida o que estaban transitando un tratamiento durante el período de debate de la Ley de fertilización asistida (26.862/13), y luego de su promulgación a nivel nacional. Como ejes de la puesta en escena mediática encontramos nuevamente el recurso a datos estadísticos -"gracias a estos tratamientos in vitro que creó el Dr. Edwards, un médico británico, hace treinta años nacieron en este mundo ya cuatro millones de seres humanos, de los cuales Pasqua [refiere al Dr. Sergio Pasqualini, un especialista argentino muy reconocido] ya trajo cuatro mil"; "una de cada seis parejas necesita esta ley" ambas afirmaciones de Marisa Brel -periodista de espectáculos que tuvo a su primera hija por fertilización in vitro y a su segundo hijo a través de una subrogación de vientre- ${ }^{18}$; la difusión de información relativa a procedimientos y organismos de gestión - "Si vivís en Provincia de Buenos Aires te podés atender gratis con residencia de dos años" ${ }^{19}$, "y si las obras sociales y prepagas

17. www.youtube.com/watch?v=YUpR9SL4UBU. Recuperado el 28 de marzo de 2017.

18. www.youtube.com/watch? $\mathrm{v}=\mathrm{zbsFgU}-\mathrm{LxcQ} \& \mathrm{t}=5 \mathrm{~s}$ Recuperado el 28 de marzo de 2017.

19. www.youtube.com/watch?v=dhSXDNFnGpg\&t=43s. Recuperado el 28 de marzo de 2017. 
dicen que no, insistan" ${ }^{20}$, "se puede acceder a dos tratamientos, uno por año calendario" ${ }^{21}$, entre muchos otros ejemplos.

En el año 2010, dos antes de la promulgación de la Ley de Identidad de Género (26.743/12) y como parte de las acciones judiciales llevadas adelante durante el proceso de impulso y sanción de la normativa, Florencia de la V -nombre artístico de Florencia Trinidad, una reconocida comediante y conductora- consiguió que la justicia fallara a favor del cambio registral de sus datos tanto en la partida de nacimiento cuando en su Documento Nacional de Identidad. En el living del programa de Susana Giménez lo relataba del siguiente modo:

"Fue un fallo único en Argentina porque lograron que me hicieran modificación de partida. Por eso es importante, no solamente me cambiaron el nombre... porque en general lo que siempre se ponía en la partida de nacimiento original se ponía un papelito pegado así arriba, de dudosa procedencia, bueno esta persona se llama así pero con tu nombre así gigante de hombre. En este caso no, se hizo modificación de partida y en donde dice sexo aparte de decir 'todos los días' [sonríe] dice 'femenino"” (Florencia de la V).

Susana Giménez acota sorprendida, "Uau, esa explicación, ¡impresionante!” y luego le pregunta si ahora le resulta más sencillo cruzar la frontera de Estados Unidos. Florencia de la V responde y luego retoma la intervención reinscribiendo el fallo por su identidad en la lucha por la igualdad de derechos de cara a la sanción de una Ley de Identidad de Género. Veremos esto en el siguiente punto.

\section{"Todas y todos tenemos los mismos derechos". Escenario de debate púbico y enunciación de demandas}

Así como en el apartado anterior focalizamos en la producción de información, la exposición de datos, la difusión de procedimientos y agentes que adoptar o a los que acudir frente a ciertas vulneraciones de derechos o problemáticas y que en muchos casos se recurría para ello a un lenguaje técnico-jurídico, en este apartado me interesa puntualizar la inclusión de un lenguaje de derechos en la mediatización de cuestiones relativas a géneros y sexualidades.

Esto no sólo implica el recurso a ciertas categorías propias de una perspectiva de derechos -discriminación, igualdad-desigualdad, derechos humanos, ciudadanía- ciudadanía de segundasino también la caracterización de las responsabilidades y obligaciones de las instituciones, clase dirigente y otros actores, de los propios ciudadanos en su vínculo político con los representantes parlamentarios. De este modo, los testimonios aportados por las celebridades locales funcionan aquí como ejemplo de una problemática social y se ofrecen como medio para presentar públicamente una situación de discriminación o desigualdad de un colectivo más amplio.

Florencia de la V, en la entrevista referida más arriba, sostuvo:

"Me encanta, me encanta poder ayudar a la gente y que este primer paso sea un puntapié para que se pueda llevar al congreso a debatir (...) están saliendo muchísimos

20. www.youtube.com/watch?v=zbsFgU-LxcQ\&t=5s. Recuperado el 28 de marzo de 2017.

21. www.youtube.com/watch?v=4UZtraCxeYs. Recuperado el 28 de marzo de 2017. 
amparos [judiciales] así que es maravilloso lo que está pasando. Viste que al gobierno se le critican muchísimas cosas, puede haber gente que pueda estar de acuerdo o no, pero hacen cosas y en este caso van a ayudar a muchísima gente. Con el matrimonio igualitario y este cambio posible de la ley de nombre [refiere a la ley de identidad de género] va a ser algo muy fuerte. O sea, no importan los gobiernos, porque nosotros pasaremos y los gobiernos también pero las leyes quedarán. Todos y todas tenemos los mismos derechos" 22 .

En un sentido similar pueden leerse las intervenciones de Ronnie Arias -conductor de radio y televisión-, entrevistado en el magazine AM luego de la promulgación de la ley de Matrimonio Igualitario (26.618/10) y del cantante Ricky Martin en una entrevista en el programa de Susana Giménez también posterior a la sanción de esa ley.

Verónica Lozano - conductora de AM- le pregunta a Ronnie Arias por sus "fantasías en relación al matrimonio" y él contesta:

"En realidad más que tener esa fantasía de casarme tenía la fantasía de no ser más una persona de segunda, de no ser más un tipo que no vale lo mismo que cualquier otro, de tributar como soltero cuando hace 15 años que convivo, de no tener el derecho a que si me muero la persona que me acompañó durante toda mi vida se quede con mi guita, con mis zapatillas". ${ }^{23}$

Susana Gimenez encontró más dificultades para formular la pregunta en la entrevista a la celebrity internacional Ricky Martin y dio un rodeo rápidamente sorteado por el cantante:

SG: Se aprobó el año pasado... el año pasado, que se puede casar la gente... ehhh... la gente... digamos... con el...

RM: ¿Del mismo sexo?

SG: ¡Del mismo sexo!

RM: ¡Bravo Argentina, un aplauso, venga, venga Argentina! ¡Que se sienta! ¡Qué viva la igualdad!

SG: ¿Te gustaría?, ¿podrías hacer eso de llegar a casarte?

RM: ¿En mi tierra? Tu dame la opción, a mí dame la opción, ahora mismo no tengo la opción. A mí me parece un poco absurdo pero bueno, poco a poco vamos cambiando y como comunidad LGBT vamos dando pasos sólidos, lentos pero seguros y yo creo que el hecho de que Argentina diga no a la discriminación en un caso tan simple como este ¿no?, los derechos humanos, pues crea un precedente maravilloso para el resto de Latinoamérica. Luego de Argentina vino la ciudad de México, inclusive ahora Brasil también, o sea, hay algo sucediendo que es muy bonito.

SG: El efecto bowling

RM: ¡Claro! Susana, es que yo no estoy pidiendo más derechos, tampoco quiero menos, yo quiero igual. Igual que tu igual que yo, es super básico. ¿Me voy a casar?

22. www.youtube.com/watch? $\mathrm{v}=\mathrm{qXUnJi9tNOA}$. Recuperado el 28 de marzo de 2017.

23. www.youtube.com/watch?v=JRGjfJF1PPo. Recuperado el 28 de marzo de 2017. 
No. No, en este momento estoy con mi pareja muy estable no es algo que se está hablando, estamos muy bien como estamos, pero queremos esa opción, punto.

SG: Para sentirte igual a todos.

RM: Claro, ¿por qué ciudadano de segunda clase, no ${ }^{24}$

Como mencionamos cuando caracterizamos el pasaje de los activistas famosos -aquellos militantes de organizaciones de la sociedad civil que participaban de los programas televisivos de alta audiencia- a los famosos activistas -las celebridades locales que formando ya parte de esos espacios televisivos desplazaban sus relatos hacia la demanda de derechos frente a ciertas coyunturas personales o políticas- , los procesos de discusión pública en torno de los derechos relativos a géneros y sexualidades que se fueron conquistando en la última década estuvieron protagonizados fuertemente por personalidades del mundo artístico. En el caso del debate por la Ley de Matrimonio Igualitario, la comunidad artística participó en actividades públicas, campañas desarrolladas por las organizaciones LGBT, haciendo incidencia en los medios de comunicación. Andrea del Boca -una de las actrices de telenovelas más reconocidas de Argentina- se refería a este tema en un programa metatelevisivo -TVR, Televisión Registrada- en el sentido que venimos observando:

"Me duele que todavía se siga diciendo el matrimonio homosexual porque en realidad se llama matrimonio igualitario porque tiene que ver con la ley, tiene que ver con que todos tenemos los mismos derechos y es un derecho constitucional de todos los hombres y mujeres más allá de su elección sexual. Entonces, no pensar en el sufrimiento de tanta gente y tomarlo tan livianamente, digo, cada uno puede tener su opinión y hay que respetarla porque para eso también es la democracia pero también hay que ponerse por un minuto en el lugar del otro" 25 .

Otro de los rasgos de la constitución de los programas de chimentos y espectáculos en espacios de enunciación de demandas es, como dijimos, la interpelación directa al estado -en sus diferentes poderes-, a la clase política y a otros actores (empresas privadas, por ejemplo).

En relación a la Ley de Fertilización asistida, Jorge Rial introducía la entrevista a un periodista deportivo que acababa de ser padre por medio de técnicas de reproducción asistida, diciendo:

"Es un tema que, repito, le importa a muchísima gente, es un tema trascendente y los políticos lo tienen cajoneado. Se había prometido que el 17 de octubre se trataba, no se trató. Yo entiendo que están con la Ley de Medios, si se lo sacan de encima rápido métanse en este tema, van a hacer feliz a mucha gente. No siempre la felicidad del político es la felicidad de todos los demás (...) las preocupaciones personales políticas y partidarias, que no son las preocupaciones del día a día y hay temas importantes que por ser personales no son egoístas, porque cada diputado y cada senador representa a cada uno de nosotros. Quiero decir esto porque hay muchísimas familias, muchísimas, más de las que se imaginan que están buscando un hijo desesperadamente por la fecundación in vitro que es carísima, que la mayoría de las obras sociales no la cubre porque creen que ser padres es... no sé, un lujo, un privilegio y es una necesidad.

24. www.youtube.com/watch?v=NMt44Utw64Y. Recuperado el 28 de marzo de 2017.

25. www.youtube.com/watch?v=7D0Syc5KvP0. Recuperado el 28 de marzo de 2017. 
Porque además no es fácil moverte en un ambiente donde cuando alguien hace este tipo de tratamiento después es mirado de otra manera. De hecho, yo que soy padre del corazón he sufrido muchas veces la mirada de 'este es raro'. Y encima no te acompaña la sociedad política en hacer ley la fertilización asistida, de hacerlo rápido de hacerlo fácil (...) Hay cosas necesarias que hacen a la gente común, el que quiere ser padre quiere ser padre y necesita la ayuda de ustedes los políticos. Está la ley ahí durmiendo, son miles y miles de familia que la están pidiendo ya hay in vitro que se están haciendo en la provincia de buenos aires, hay que firmarlo ya. Empiecen a laburar para la gente." 26

Laura Miller, en la entrevista ya referida interpelaba a los dirigentes y funcionarios:

"Nos están matando. Ayer tiraron una chica por un barranco, el otro día en Caballito otra se juntó con su ex y la apuñaló delante de todo el mundo. ¿Nadie está viendo eso? Las autoridades, los políticos, ¿no están viendo eso? Porque si ustedes sacan esta ley es la mejor campaña que pueden hacer, la mejor. Yo no tengo la camiseta de ningún partido político, no me importa el color que sean pero tienen que hacer algo con esto",

e interpelaba también a la sociedad: "el pueblo tiene más poder que nadie porque los que están ahí están ahí gracias a nosotros, entonces nosotros tenemos que exigir".

Un año después de la sanción de la Ley de Identidad de Género, el periodista de chimentos Marcelo Polino publicó un libro en el que dedicaba un capítulo a su vínculo con Florencia de la V, la ya citada comediante y conductora; el capítulo se titulaba "meábamos en la misma lata". Esta frase desencadenó horas de debate en televisión y páginas de las revistas de espectáculo menos sobre la pelea entre el autor del libro y la comediante, que sobre la identidad de género de ésta última.

En ese momento Florencia de la V tenía en la pantalla de Telefé un programa propio -La Peluen el que hizo un extenso descargo y sentó su posición sobre los hechos. La intervención inicia con la descripción de la rutina cotidiana de la comediante durante día anterior, escenas familiares y domésticas se suceden hasta que se encuentra mirando un programa metatelevisivo -Bendita TVen el que emiten un informe sobre la pelea. Florencia de la V no escatima en detalles sobre las sensaciones que experimentó en ese momento y cierra el descargo diciendo:

“(...) Mientras escuchaba todo el informe se me heló la sangre. Se me heló la sangre. Lo tenía a mi hijo en brazos Sentía que a mi hijo casi no lo podía sostener, que los brazos... y dije, no voy a cambiar... para mi sorpresa no terminaba ahí, continuaba con una declaración de la conductora Viviana Canosa [otra de las conductoras emblemáticas de programas de chimentos locales], donde decía que le encantaba, que se divertía porque era una pelea de dos tipos. Así muy suelta de cuerpo, En ese momento yo ya tenía los ojos llenos de lágrimas. Vuelven al piso y hacen como un pequeño descargo así los panelistas, Beto [el conductor] en algún momento ya había dicho, 'no, pero nosotros la vemos como una mujer a ella', pero remata el tape diciendo bueno lo que

26. www.youtube.com/watch?v=3JY9HX4MOHM. Recuperado el 28 de marzo de 2017. 
pasa es que ellos se están midiendo a ver quién la tiene más larga. Y ahí me puse a llorar desconsolada, en ese momento yo casi no podía sostener a mi hijo que estaba tomando la mamadera y Pablo se dio cuenta y ante esa situación lo llevó a su cuarto y me quedé sola en mi cama, sola, llorando desconsoladamente. Ustedes seguramente se preguntarán claro es por lo que dijeron, yo realmente no creo que deba ser grato para ninguna persona que tu sexualidad, tus genitales, se pongan tan crudamente ante millones de personas en horario central televisivo, pero lo que me provocó un profundo dolor que fue lo que hizo que estas lágrimas no pararan de salir de mis ojos, fue que no le dieron el debate que la situación merece. Porque se está hablando de una persona, no se está hablando de una cosa. Yo la verdad, Viviana, no sé qué sociedad le querés dejar a tu hija Martina, pero yo claramente no es la sociedad que quiero para mis hijos. Yo quiero otro país, nosotros somos ejemplo en el mundo con muchísimas cosas, con los derechos humanos, con la ley de matrimonio igualitario, con la ley de identidad pero realmente en este país, la igualdad aún no existe. Yo saben una cosa, gran parte de mi vida sentí vergüenza, nunca lo dije, sentí vergüenza de mí, de ir a un banco de mostrar mi DNI de que me escuchen la voz y saben una cosa, un día me miré al espejo y me dije vergüenza de qué, vergüenza de qué, de ser diferente, de pensar distinto, de amar y dije, nunca más, nunca más voy a sentir eso, por eso hoy yo me comprometo. A usted señora presidenta le digo, cuente conmigo yo voy a trabajar incansablemente no solamente con su gobierno, con el que venga y los que vendrán, con todos los que me quieran escuchar, pero yo no quiero que ningún hombre, mujer, adolescente o niño sienta lo que yo sentí. Nosotros como comunicadores tenemos un deber, entonces, si una persona se refiere a otra de una manera discriminatoria yo en mi programa diría momentito, momentito" ${ }^{27}$. Toma su Documento Nacional de Identidad y dice a cámara conmovida: "mi nombre es Florencia Trinidad, madre de Paul e Isabella Goycochea, señora del Dr. Pablo Alejandro Goycochea, mujer y argentina", apaga la luz de la peluquería y sale de escena.

Tomé este fragmento no sólo porque permite abundar sobre lo ya dicho en relación la inscripción de tópicos de géneros y sexualidades en un marco de derechos, sino porque hace explícito el modo en que ese marco debe modificar las características y condiciones en que se debate y tramitan públicamente estas cuestiones.

\section{"Cuando uno está en los medios hay también una responsabilidad pública". Discusión del rol de los medios}

En este apartado quisiera hacer una breve mención a dos modos de aparición de los medios que se vincula también, y aunque exceda las posibilidades de este trabajo profundizar en ello, con que la última década en Argentina estuvo signada por la intensificación de la discusión pública en relación a la función social de los medios de comunicación masiva. Este debate se coló de algún modo en el propio discurso mediático y en los casos que nos ocupan aparece en referencia

27. www.youtube.com/watch?v=cNyYLY7QQqc. Recuperado el 28 de marzo de 2017. 
a las consecuencias de la acción o de la omisión por parte de las empresas de comunicación. Lo que queda claro es que no existe una idea sobre la neutralidad o inocuidad de los discursos mediáticos, ni siquiera de aquellos habitualmente pensados como banales. Otra de las referencias que aparece con frecuencia es la de la "responsabilidad" de los medios de comunicación en el abordaje y la difusión de ciertas problemáticas, lo que he llamado en otros trabajos "politización mediática" (referencia eliminada para evaluación, 2012), que ubica a los medios y a la televisión en particular en una relación de interlocución entre la sociedad y el Estado, tomando a su cargo las preocupaciones sociales e interpelando a las instituciones para la intervención.

"Los noticieros no pasan ni un cuarto de lo que pasa en el mundo y en Argentina, sobre todo, no pasan ni un cuarto de los asesinatos, las cosas de violencia, no lo pasan", sostiene Laura Miller. Jorge Rial la interrumpe y agrega, "lo que pasa es que todavía lo disfrazan bajo el título erróneo de crimen pasional". ${ }^{28}$

"No se dice el trans, se dice la trans y un hombre gay debería saberlo mejor que nadie", afirmaba Sofía Gala Castiglione -actriz e hija de Moria Casán, una de las vedettes más importantes de Argentina- en el panel del programa de debate que acompañó las emisiones de Gran Hermano 2015 por el canal América TV. Ese año había ingresado a la casa del reality Valeria, una participante que se autodefinía trans y que puso en escena nuevamente la discusión acerca de la identidad de género, su relación con la elección sexual y, especialmente, el desacople entre las normas jurídicas y las regulaciones sociales. Aquello que resultaba evidente en la letra de la ley -que había que referirse a Valeria en función a su identidad autopercibida- era materia de incomodidades y disputas en el piso del Debate. Por supuesto esto resulta casi una obviedad en la medida en que esos desacoples forman parte de la vida social -los tiempos de la ley no son los tiempos de la cultura- y en la medida en que la propia industria del espectáculo mercantiliza los issues que registra como controversiales (Lull, 1999). El amplio, heterogéneo y difuso terreno de lo que la industria identifica como "sexualidad" continúa siendo uno de ellos.

La razón, entonces, por la que tomo este ejemplo es que dos de los argumentos esgrimidos en la discusión tuvieron que ver con la existencia de una ley que había que respetar y con la responsabilidad de las y los comunicadores en relación al tratamiento de temas que involucran la identidad e intimidad de los sujetos. Es decir, la industria del espectáculo televisivo rentabiliza la sexualidad en la medida en que genera interés y conmoción en la audiencia; las audiencias se movilizan en torno a estos temas, discuten, toman posición, disfrutan del escándalo y la exposición de la intimidad. En definitiva, ponen en juego -revisan, contrastan, afirman- sus concepciones morales y éticas (Lull, 1999). Por sobre ellas aparece en este ejemplo el peso de la Ley como un igualador social.

Un episodio sucedido dentro de la casa de Gran Hermano en el que un participante refirió a Valeria en masculino, obligó a los panelistas del Debate a sentar posición al respecto. Victoria Vanucci -ex vedette y actriz que participaba en ese momento del elenco del programa- manifestó su incomodidad en relación a tratar a Valeria en femenino y entabló una intensa discusión con Sofía Gala Castiglione que versó centralmente sobre el derecho a opinar sobre la identidad de Valeria.

28. Video Miller. Recuperado el 28 de marzo de 2017. 
“(...) una no estaba hablando de Valeria, de la sexualidad de Valeria. Pero sí, una una tiene una opinión y a veces siento que uno tiene miedo de dar esa opinión...

(La conductora a un especialista): ¿y por qué se siente este miedo, Gervasio?

(Gervasio): Yo creo que porque hay un forzamiento, una exigencia de que ya tenemos que saber todos las cuestiones de identidad de género. Esto lleva un proceso. Yo también puedo decir el trans en lugar de la trans. Estamos muy ansiosos Pamela con este tema.

(La conductora a Sofía Gala): Sofía Gala está por explotar. Hacé tu descargo Sofía.

(Sofía Gala): "yo no digo que la gente no tenga todavía problemas de adaptación y que la gente piense lo que se le canta pero hay leyes y hay mujeres y hombres que pelearon por estas leyes y justamente pelearon para que se los respete. Tu opinión te la podés guardar y más si sos un personaje público...

(Victoria Vanucci interrumpe): Yo puedo respetar la ley pero no estar de acuerdo con la ley y no me tengo por qué guardar la opinión tampoco. Porque además si estás en un debate estás precisamente para decir lo que pensás.

(Sofía Gala): Yo entiendo que vos no estés de acuerdo, vos o cualquier persona, pero me parece que cuando uno está en los medios hay también una responsabilidad pública que no es lo mismo que vos opinando con tu gente". ${ }^{29}$

Al día siguiente en el programa Intrusos, la panelista Marina Calabró retoma el punto para sostener: "Sofía Gala dijo 'tu opinión te la podés guardar' en el sentido de que la ley nos impone referirnos públicamente en base a lo que la ley estipula" ${ }^{30}$.

\section{"Esto tal vez le vaya a servir a alguien". Generar identificación y servir a la comunidad}

Jorge Rial vuelve del corte y dice: "Explotó el twitter. Explotó el tema de fertilización asistida que acabamos de hablar y que vamos a hablar en un rato con el Pollo Vignolo [un periodista deportivo]. Es impresionante el twitter, los tweets que me están llegando de la gente agradeciendo que hablemos del tema, que nos podamos dar un minuto en medio de tanta frivolidad para parar la pelota y hablar de la fertilización asistida." 31

No sólo los programas tienen que ocuparse de estos temas porque le sirven a la audiencia, que entonces se muestra agradecida, sino que las personalidades del espectáculo tienen un rol que cumplir:

"A las personalidades, a los artistas, a la gente que realmente tiene influencia y que los siguen millones y millones de seguidores a Marcelo, a Susana, a la señora Mirtha a vos Jorge, a todos loco, hagan algo! Yo soy cantante, soy actriz no tengo nada que ver con la política pero esto a mí me pasó porque esto no discrimina clase social... entonces ojalá que tenga mucho rating esto que todo el mundo empiece a hablar de

29. www.youtube.com/watch?v=Efzih4zN7Iw. Recuperado el 28 de marzo de 2017.

30. www.youtube.com/watch?v=3ZzjEKNLII4. Recuperado el 28 de marzo de 2017.

31. www.youtube.com/watch?v=cNyYLY7QQqc. Recuperado el 28 de marzo de 2017. 
esto de verdad... y no le quieran poner un costado amarillista a esto y que después la gente se cuelgue hablando pavadas y mentiras. Realmente tenemos que hacer algo (...) Lo importante es contarlo porque... Moria, Moria por ejemplo que yo sé que lo vivío porque lo contó... y eso, eso es fundamental, que las personas del espectáculo que son totalmente influyentes en los medios, en la gente, que se sienten a decirlo o que lo estén nombrando como lo hice yo que soy un punto al costado pero no importa, es importantísimo porque la gente no toma conciencia" (Laura Miller)

Cuando la violencia de género todavía no era tematizada como tal, hubo un episodio de aquellos que son recordados como clave en la televisión argentina, Andrea del Boca mostró en cámara un moretón que tenía en la pierna producto de una agresión de su ex pareja: "Te voy a mostrar porque creo que son muchas cosas y también esto tal vez le vaya a servir a alguien -muestra el moretón- esto no es maquillaje, esto no es una telenovela. ${ }^{32}$

"A ver, yo quise ayudar desde mi lugar de artista... porque el sentido del video era ayudar y hay chicas que lo miran y me dicen, 'loca, me ví reflejada y ahora lo quiero dejar"” (Laura Miller)

Marcela Tauro, panelista de Intrusos, en relación a las razones por las hablaban sobre fertilización asistida y contaban la historia del Pollo Vignolo: “(...) además por muchas parejas que están mirando el programa y deben estar pasando una situación asî".

Marisa Brel, en la citada entrevista también sobre fertilización asistida: "a mí me gusta mucho hablar de estos temas para despertar conciencia”.

Pamela David, conductora de Desayuno, introduciendo el segmento citado sobre violencia de género: "Obviamente desde los programas de televisión y en este programa hemos tocado muchas veces este tema y la idea es concientizar y ayudar. A vos que estas del otro lado y que estás pasando una situación similar. Que hagas la denuncia, que no dejes pasar un minuto más de tu vida por este calvario". Aparece el zócalo con la línea 144 para denuncias de situaciones de violencia de género.

Dos aspectos que aparecen en estos ejemplos y que son los últimos que quiero señalar; por un lado, el acercamiento de las personalidades del espectáculo a la audiencia -"esto que me pasa seguro te está pasando a vos"-. Si ya se había producido en la televisión el movimiento por el cual el sistema de famosos había incorporado a su exposición pública el tratamiento de la intimidad, ahora esa intimidad es además una "intimidad común" cuyos avatares no discriminan por cuestiones de clase, posición en la legitimidad cultural -le pasa a la actriz de culto y a la vedette de la temporada- y cuya distinción central parece residir en que las personalidades del espectáculo pueden acceder con más frecuencia a los medios de difusión y transformarse en una voz pública de referencia ${ }^{33}$.

32. www.youtube.com/watch?v=X7eBO5jJp-M. Recuperado el 28 de marzo de 2017.

33. Hice la salvedad relativa a la frecuencia porque, por supuesto, ciertos temas de interés público han estado orientados por un proceso inverso: una persona sin notoriedad pública que la adquiere a partir de su exposición en relación a un caso de relevancia social. Estas personalidades, en general, transitan otros circuitos mediáticos. 
Por otro, la concepción de que lo que se está haciendo puede tener una utilidad social. Si los programas de chimentos y el mundo del espectáculo televisivo -y por carácter transitivo sus protagonistas- ocupan un lugar de segunda en la legitimidad de la producción cultural en virtud de las razones que he esgrimido largamente al inicio de este trabajo, la tematización de ciertos tópicos y el modo de tratamiento elegido, puede permitir construir "respetabilidad" comunicacional y afirmar una función social valiosa.

Por supuesto, lo dicho hasta ahora no implica pensar el espacio televisivo como un terreno de mero pluralismo y defensa de los derechos de las personas sino como un espacio de producción cultural plagado de contradicciones. Advertir los pliegues y solapamientos de la superficie televisiva permite no desestimar el lugar de la instalación de tópicos disidentes, aun cuando sea con costos que todavía pueden parecernos altos: que las "divas de la televisión" le pregunten a dos entrevistadas qué hicieron para que les pegaran ${ }^{34}$, que en una mesa conformada por legisladores, activistas y profesionales se le pregunte a un diseñador de modas muy reconocido si dos gays en pareja que adopten un chico podrían cometer violación ${ }^{35}$, que frente a una figura internacional como Ricky Martin se hable del matrimonio igualitario en términos de derechos y que pocos meses después la misma conductora le diga a un famoso local con reputación de "mujeriego": "peor sería que te gusten los hombres!" 36 , o -si para dar un último ejemplo de todos los posibles- el mismo conductor tematiza con mucha frecuencia la violencia de género y luego adopta posiciones sexistas y discriminatorias en otras emisiones de su programa, no obsta que en esos livings, mesas y estudios se haya puesto en escena el matrimonio igualitario o la violencia de género como parte del debate de la cosa pública en clave televisiva. Y que, además, los modos en el que las audiencias se vinculan con esa puesta en escena compleja y contradictoria sea imposible de inferir a partir del análisis de los textos mediáticos ${ }^{37}$.

\section{Tres derivas y una anécdota}

Para terminar, quisiera plantear brevemente tres derivas a las que nos lleva un análisis como el que traté de plantear en este trabajo y que pretenden abonar a la reflexión sobre los modos de abordar el entretenimiento televisivo (y de los contenidos mediáticos en general).

En primer lugar, se pone de relieve la necesidad de dar cuenta de la espesura y complejidad de los productos televisivos en los análisis en producción. Esto implica distanciarse de los abordajes

34. www.youtube.com/watch?v=MkXxAOFBu2o (Susana Giménez con Victoria Vanucci); hwww.youtube.com/wa tch? $=-9 X 2 \mathrm{u} 03 \times 68 \mathrm{E}$ (Mirtha Legrand con Laura Miller)

35. www.youtube.com/watch? $v=x d 1 H c O Q Z \_b Y$ (Mirtha Legrand con Roberto Piazza)

36. www.youtube.com/watch?v=aSAyJd-wgl8 (Susana Gimenez con Matías Alé)

37. En el momento de escritura de este trabajo nos encontramos realizando con un equipo de colegas un estudio que incluye entrevistas y grupos focales con audiencias de programas de entretenimiento y espectáculo de televisión abierta en tres ciudades capitales de Argentina (Buenos Aires, Rosario y Córdoba). La violencia de género -ejemplificada con un caso resonante de los últimos meses- fue un tópico ineludible en todos los grupos en las cuatro zonas. El modo en que los participantes refieren, cuestionan, analizan el tratamiento del caso -que involucra dos "famosos" jóvenes que trabajan en uno de los programas de mayor rating de la televisión local- lejos de expresar un consumo acrítico o banal de los contenidos, permite observar los desplazamientos y apropiaciones que las audiencias operan sobre los textos mediáticos. También, el modo en que los articulan con otros contenidos de los propios medios y con experiencias que los exceden, como el movimiento NiUnaMenos. 
confirmatorios -aquellos que encuentran en los materiales sólo lo que van a buscar- para permitir que las textualidades se muestren en sus múltiples dimensiones. Solemos detenernos en una pequeña porción de lo que ofrecen y solemos hacerlo orientadas/os por aquello que esperamos encontrar. Como dijimos al inicio de este artículo, en el caso de los programas de chimentos o entretenimiento podemos rápidamente "confirmar" que son sexistas, discriminatorios y que abordan de modo superficial algunos tópicos de relevancia social y sumarnos así a las tendencias generales de lo "ya dicho". Lo que no deberíamos permitirnos es obturar la pregunta por el "¿qué más?" o lo único que habremos confirmado es que los estudios de comunicación y cultura se han quedado ya mudos en relación a objetos sobre los que los sujetos hablan todos los días. En ese mismo sentido, es necesario poder valorar los productos televisivos en sus tensiones y contradicciones; pienso aquí no sólo en aquellas que aparecen en un mismo programa o formato sino aquellas que, como hemos mencionado más arriba, se producen en el fluir del discurso televisivo. Esto ha sido ampliamente señalado en los trabajos ya citados de Jesús Martín Barbero (1987) y también en los más recientes de Omar Rincón (2015). En última instancia, ¿por qué habríamos de exigirle a los contenidos televisivos una coherencia que no se expresa ni en nuestras experiencias cotidianas ni en las relaciones y posiciones sociales que sostenemos y mucho menos en las instituciones que transitamos y con las que nos vinculamos?

La segunda deriva, está relacionada con la puesta en discusión de una antigua pero persistente distinción entre las funciones educativas, informativas y de entretenimiento que despliega la televisión. Autores como Imbert se preguntan "¿en qué medida -una televisión fundada en el entretenimiento y la diversión- es compatible con una función didáctica, una misión educativa?" (2003: 36-37) y se propone mostrar los peligros de banalización y el riesgo de que la diversión aparte de la reflexión. Más allá de que no es el objetivo de este trabajo discutir las concepciones sobre educación y sobre el proceso de enseñanza-aprendizaje que subyacen a estos posicionamientos, es importante señalar -tal como lo hace el propio autor- que se está distinguiendo "la relación cognoscitiva (basada en el aprender) de la relación emotiva (basada en el sentir)" (:40) como si la emoción, las sensaciones, el placer y el rechazo, no formaran parte de modos del conocimiento humano. Sería importante aquí profundizar la revisión de la jerarquización cultural que opera tras estos argumentos: no sólo existen modos legítimos de aprender sino espacios legítimos para desarrollar los aprendizajes. Esto nos conduciría además a revisar los contenidos ligados a esos aprendizajes, ¿qué conocimientos son concebidos como educativos en el contexto de la producción televisiva? Recordemos por ejemplo que una de las funciones centrales de la cultura popular y masiva ha sido tomar a su cargo la educación moral y sentimental del pueblo (Thompson, 1990; Barbero, 1992; Cruces, 2008; Lull, 1999, entre muchos otros). Un último señalamiento en este sentido relativo a los mundos posibles y a las funciones de la televisión (entretener, informar, educar): la categoría infoentretenimiento permitió designar el modo en que la retórica y ciertos aspectos temáticos del entretenimiento permearon el espacio informativo, sería bueno pensar, a la inversa, el modo en que el espacio de entretenimiento opera como fondo de recursos informativos y de aprendizaje social.

La tercera y última deriva está vinculada a la centralidad de la perspectiva de los actores en los análisis sobre el entretenimiento televisivo. Conocer la experiencia de quienes consumen y de quienes producen los materiales que analizamos es imprescindible para poner en tensión las inter- 
pretaciones que realizamos de los contenidos con aquellas que hacen sus audiencias. Sin dudas, esto nos conducirá a curarnos del "síndrome de propiedad de la teoría"; las audiencias formulan teorías sobre los medios, desarrollan habitualmente crítica cultural y mediática, distinguen estrategias enunciativas, procedimientos técnicos al servicio de la producción de sentido, entre muchas otras operaciones analíticas a las que estamos habituados quienes nos dedicamos a la investigación como un trabajo.

Y entonces es momento de la anécdota. En mayo del año 2014 registré una conversación en un colectivo de la ciudad de Buenos Aires, cerca de Plaza Once, entre dos mujeres de entre sesenta y setenta años. Lo que conversaron esas mujeres se asemeja mucho al epígrafe que elegí para iniciar el artículo -el diálogo entre dos personajes de una ficción de mucho éxito del año 2016 en el que "La negra Graciela" explica que la información que tiene acerca de cómo proceder en un divorcio controvertido y que involucra un patrimonio significativo la ha "absorbido" de los programas de la tarde- en la medida en que expresa en clave televisiva la experiencia cotidiana posible para las audiencias. Encontrar en los programas de chimentos y espectáculos una fuente de recursos e información para procesar eventos de la vida cotidiana y -más aún- poder enmarcar estos eventos en el marco de derechos que les asisten como ciudadanos.

Mujer 1: La nena le dijo a la Cuca que no sabe por qué la mamá la quiere con ella si se va los viernes y la deja ahí y ya no aparece hasta el lunes. La Cuca después no la ve hasta el otro viernes, no sabe de ella y la nena los lunes no se quiere ir, pero la madre se la lleva igual. La Cuca es la abuela, ¿viste? Mejor si se quedara con ella, pero ya no sabe cómo hacer porque no se la pueda sacar, la otra es la madre.

Mujer 2: Pero tal vez el juez la escuche a la nena, porque ahora los jueces escuchan a los menores. Mirá lo que le pasó a Rial, las nenas pidieron ir con él y el juez atendió $^{38}$. Vos decíle a la Cuca que insista. (7 de mayo de 2015, Línea 7 cerca de Plaza Once)

\section{Bibliografía}

Abu- Lugod, L. (1997). La interpretación de las culturas después de la televisión. Revista Etnografías contemporáneas, año 2005, Buenos Aires, UNSAM. Spataro (tesis)

Alvarado, M. (2014). Mujeres, chismosas e informadas. Construcción de feminidades en el consumo de programas de chimentos. Tesina de grado para la Licenciatura en Comunicación Social, Universidad de Buenos Aires, mimeo.

Arfuch, L. (2002). El espacio biográfico. Dilemas de la subjetividad contemporánea. Buenos Aires: Fondo de Cultura Económica.

Bennett, J. (2011). Celebrity and politics. Celebrity Studies, 2: 1. Londres: Routledge.

Best, B. (1997). Over-the-counter-culture. S. Redhead (ed.), The clubcultures reader. Readings in popular culture studies. London: Blackwell Publishers.

38. Refieren al controvertido y público proceso judicial de divorcio del conductor Jorge Rial que involucró la discusión por la tenencia de las hijas. 
Boschiero, Ch. (2013). Derechos humanos, género y medios de comunicación en Argentina.: la Ley de medios analizada desde un enfoque de género. Tesis de maestría. Universidad Nacional de San Martín, Centro Internacional de Estudios Políticos.

Butler, J. (2002). Cuerpos que importan. Sobre los límites materiales y discursivos del "sexo". Buenos Aires: Paidós.

Cáceres, M. D. (2000). La "crónica rosa" en televisión o el espectáculo de la intimidad. CIC, Cuadernos de Información y Comunicación, (5). Madrid.

Cáceres, M. D. (2010). El discurso de la televisión en la cultura. Del espectáculo: los procesos de mediación en los programas de la telerrealidad. SPHERA PUBLICA Revista de Ciencias Sociales y de la Comunicación (10). Murcia, España.

Carlón, M. (2005). Sobre lo televisivo. Dispositivos, discursos y sujetos. Buenos Aires: Ediciones La Crujía.

Casetti, F. \& Odin, R. (1990). De la Paleo a la Neo televisión. Aproximación semiopragmática. Communications, (51). Traducido en Del Coto, María Rosa (comp) (2008): La discursividad audiovisual. Aproximaciones semióticas. Buenos Aires: Editorial Docencia.

Cingolani, G. (2006). La televisión, objeto de la televisión: archivo, crítica y juicios de gusto en los programas meta-televisivos y de espectáculos. Oficios Terrestres, XII, 18. La Plata.

Cruces, F. (2008). Matrices culturales: pluralidad, emoción y reconocimiento. Anthropos, (219). Barcelona.

de Lauretis, T. (1996). Tecnologías del género. Revista Mora, (2). Buenos Aires: Instituto Interdisciplinario de Estudios de Género, Facultad de Filosofía y Letras, Universidad de Buenos Aires.

Debord, G. (1976). La sociedad del espectáculo. Castellote. Madrid.

Díaz, L. (2004). Autopsia a la caja sucia. Revista de Comunicación Vivat Academia, Año VII (59), Octubre.

Dieter Rath, C. (1992). Su vida por favor. Momentos autobiográficos en los programas de televisión. Revista Diálogos, (33). Federación Latinoamericana de Facultades de Comunicación Social (FELAFACS).

Eco, U. (1987). La estrategia de la ilusión. Buenos Aires: Ediciones de la Flor.

Elizalde, S. (2009). Comunicación. Genealogía e intervenciones en torno al género y la diversidad sexual. In F. Elizalde \& Queirolo (coords.), Género y sexualidades en las tramas del saber. Buenos Aires: Ediciones del Zorzal.

Ferrero, A. (2008). Chismografía crónica, consagración de seudoartistas y lucro mediático: formatos y contenidos televisivos en expansión. Questión Revista de Comunicación, 18. Facultad de Periodismo, UNLP. La Plata.

Gill, R. (2012). The sexualization of Culture?. Social and Personality Psychology Compass, 6/7. Blakwell Publishing. 
Hall, S. (1980). Notas sobre la deconstrucción de lo popular. In R. Samuels (ed.), Historia popular y teoría socialista. Barcelona: Crítica.

Hall, S. (1981). La cultura, los medios de comunicación y el 'efecto ideológico'. In J. Curran, e otros (comp.), Sociedad y comunicación de masas. México: Fondo de Cultura Económica.

Hollows, J. (2000). Feminismo, estudios culturales y cultura popular. Feminism, Femininity and Popular Culture. Manchester: Manchester University Press.

Imbert, G. (2004). De lo espectacular a lo especular (apostilla a La Sociedad del Espectáculo). CIC (Cuadernos de Información y Comunicación), (9), Madrid.

Jost, F. (1997). El simulacro del mundo. Versión, (7). México: U.N.A.M.

Jost, F. (2005). Lógicas de los formatos de telerrealidad. Revista designis, (7-8). Barcelona: Gedisa.

Justo von Lurzer, C. \& Moglia, M. (2008). La televisión que nos mira. Una aproximación panorámica a la televisión argentina de los 90 . Presentado en las XII Jornadas de Investigadores en Comunicación. "Nuevos escenarios y lenguajes convergentes", UNR, Rosario, 16, 17 y 18 de octubre de 2008. ISSN: 1852-0308.

Lull, J. \& Hinerman, S. (1999). En búsqueda del escándalo. Estudios sobre las Culturas Contemporáneas, Epoca II., V (10), Colima.

Marshall, P. D. (1997). Celebrity and power: fame in contemporary culture. Minneapolis and London: University of Minnesota Press.

Martín Barbero, J. (1987). De los medios a las mediaciones. Barcelona: Gustavo Gilli.

Martín Barbero, J. (1992). Televisión y melodrama. Bogotá: Tercer Mundo.

Mazzaferro, A. (2014). La génesis de la cultura de la celebridad. Televisión y cuerpos de la fama en Argentina (1958- 1974). Tesis para optar por el título de Doctotra en Ciencias Sociales. Universidad de Buenos Aires, mimeo.

Mcrobbie, A. (1998). More!: nuevas sexualidades en las revistas para chicas y mujeres. In J. Curran, D. Morley \& V. Walkerdine (comps.), Estudios culturales y comunicación. Análisis, producción y consumo cultural de las políticas de identidad y el posmodernismo. Buenos Aires: Paidós.

Mondelo, E. \& Gaitán, J. (2002). La función social de la televerdad. Revista Telos, (53), octubrediciembre, Madrid.

Radway, J. (1991). Conclusiones. reading the Romance. Women, Patriarchy, and Popular Literature. Chapel Hill and London: University of North Carolina Press.

Rincón, O. (2015). Lo popular en la comunicación: Culturas bastardas + ciudadanías celebrities. In A. Amado \& y O. Rincón (eds.), La comunicación en mutación. Friedrich-Ebert-Stiftung: Bogotá.

Sabsay, L. (2009). Las normas del deseo. Imaginario sexual y comunicación. Madrid: Cátedra.

Scott, J. (1990). Género una categoría útil para el análisis histórico. In M. Lamas (comp.), El género: la construcción cultural de la diferencia sexual. México, PUEG. 
Semán, P. (2015). El Posporno no es para que te excites. Revista Anfibia, Buenos Aires, julio.

Sibilia, P. (2008). La intimidad como espectáculo. Buenos Aires: Fondo de Cultura Económica.

Silverstone, R. (2010). La moral de los medios de comunicación. Sobre el nacimiento de la polis en los medios. Buenos Aires: Amorrortu.

Soto Vidal, L. (2005). Televisión rosa: amarillismo y telebasura. Chasqui, Revista de Comunicación. Editorial QUIPUS - CIESPAL, junio. Quito.

Spataro, C. (2011). ¿Dónde había estado yo?”: configuración de feminidades en un club de fans de Ricardo Arjona. Doctoral Thesis, School of Social Sciences, UBA, mimeo.

Thompson, E. P. (1990). Costumbres en común. Barcelona: Crítica.

Turner, G. (2010). Approaching celebrity studies. Celebrity Studies, 1: 1. Londres: Routledge.

Varela, M. (2010). La televisión: el espacio vacío de la crítica. Revista Imagofagia - Asociación Argentina de Estudios de Cine y Audiovisual (ASAECA), (2). Buenos Aires. 